\title{
When bicycle pump is harder to read than bicycle bell: effects of parsing cues in first and second language compound reading
}

\author{
Kristin Lemhöfer • Dirk Koester • Robert Schreuder
}

Published online: 5 January 2011

(C) The Author(s) 2010. This article is published with open access at Springerlink.com

\begin{abstract}
Reading and understanding morphologically complex words can sometimes be a particular challenge to nonnative speakers. For example, compound words consist of multiple free morphemes, oftentimes without explicit marking of the morpheme boundaries. In a lexical decision task, we investigated compound reading in native and nonnative speakers of Dutch. The compounds differed in that the letter bigram that formed the morpheme boundary could or could not occur within a Dutch morpheme, thus providing an orthotactic cue as to the position of the morpheme boundary. Native and nonnative speakers responded faster to compounds that contained such an orthotactic cue. Additional analyses showed that although native speakers used this cue for long, but not for short compounds, no such word length modulation was observed for nonnative speakers. It is suggested that orthotactic parsing cues are used during compound reading and possibly even more so in nonnative speakers.
\end{abstract}

Keywords Visual word recognition · compound reading . Orthotactic parsing cues $\cdot$ Second language speakers

Learning a second language (L2) can be a tedious enterprise, and each language has its own hurdles that

Electronic supplementary material The online version of this article (doi:10.3758/s13423-010-0044-y) contains supplementary material, which is available to authorized users.

K. Lemhöfer $(\bowtie) \cdot R$. Schreuder

Donders Institute for Brain, Cognition, and Behaviour - Centre for

Cognition, Radboud University Nijmegen,

P.O. Box 9104, 6500 HE Nijmegen, The Netherlands

e-mail: k.lemhofer@donders.ru.nl

\section{Koester}

Cognitive Interaction Technology - Center of Excellence,

University of Bielefeld,

Bielefeld, Germany make life hard for nonnative speakers. In languages such as Dutch or German, for instance, reading compounds (words with more than one free morpheme, such as doghouse) can be problematic, because they are written without interspaces or hyphens. An extreme example from German is Selbstbedienungskontoauszugsdrucker ("self-service printer for account statements"), but even in two-constituent compounds, it can be difficult to identify the constituent boundary. In the Dutch example fiets-pomp ("bicycle pump"; hyphens are included only to indicate constituent boundaries), the location of the boundary does not follow from orthotactic constraints - that is, from the rules specifying which letter sequences are well formed for a given language. The incorrect parsing *fiet-spomp also results in two legal and pronounceable letter strings and can thus not be rejected immediately. In contrast, in fiets-bel ("bicycle bell"), the morpheme boundary is easier to detect, since the bigram "sb" cannot occur within Dutch morphemes.

Whether or not orthotactic parsing cues such as the legality of the boundary bigram are used in compound processing is not only unknown for L2 speakers, it has also rarely been investigated in native speakers. Of course, not only nonnative, but also native Dutch readers might be slowed down when orthotactic cues that indicate the boundary are missing. The few studies on effects of orthotactic boundary cues in native speakers have yielded controversial results. Taft and Forster (1976) used nonwords with clear (e.g., bonchmip) versus unclear constituent boundaries (e.g., glicerax) in lexical decision and found no effect of boundary type. However, rejecting nonwords might involve quite different mechanisms than word recognition. Libben (1994) showed that parsing preferences for novel English compounds with ambiguous parsings (e.g., busheater) are influenced by orthographic factors. In a study using eye-movement measures during sentence reading, Bertram, Pollatsek, 
and Hyönä (2004) showed that Finnish readers use orthographic parsing cues together with phonological cues (vowel quality) that are specific to Finnish when reading long, but not short, compounds. In another eye-movement study, Inhoff, Radach, and Heller (2000) also included a manipulation of boundary bigram legality when investigating three-constituent German compounds with or without artificial boundary markings (added interspaces and case marking). In contrast with Bertram et al. (2004), they found no effect of the legality of the bigram straddling the constituent boundary, but the effect might have been masked by the bigger effects of the artificial boundary markings.

Of course, orthotactic parsing cues can be effective in compound processing only when compounds are decomposed-that is, when their constituents are accessed separately. A large number of studies supports decomposition (e.g., Duñabeitia, Laka, Perea, \& Carreiras, 2009; Koester, Gunter, \& Wagner, 2007; Zwitserlood, 1994), and some studies suggest that decomposition operates in parallel with a whole-word access route (e.g., Kuperman, Schreuder, Bertram, \& Baayen, 2009; Pollatsek, Hyönä, \& Bertram, 2000).

In the present study, we focused on the use of orthotactic parsing cues in native and nonnative compound recognition in Dutch, which belongs to a different language family than Finnish. The question was whether the decompositional process is influenced by orthotactic knowledge (cf. Rastle, Davis, \& New, 2004, for derivations) and whether compound parsing differs for native and nonnative speakers. Although there is some evidence that the frequencies of bigrams influence the segmentation of words into syllables as sublexical units (Seidenberg, 1987; but see Rapp, 1992), left-to-right accounts of compound parsing assume that the characteristics of the constituent boundary have no effect (Libben, 1994; Taft \& Forster, 1976).

L2 speakers may differ from native speakers regarding the use of parsing cues for several reasons. First, lexical representations of L2 words are weaker and activated more slowly than L1 words because of their reduced subjective frequency (e.g., Dijkstra \& van Heuven, 2002). This might hinder and delay the identification of the individual components of a compound, which is presumably an essential part of compound parsing. To compensate for such a disadvantage, nonnative speakers might focus on other parsing cues that are more quickly available to them, such as orthotactic cues. This should hold especially for orthotactic cues that overlap between L1 and L2, as in the present experiment.

A second possible difference between native and nonnative speakers is whether parsing is carried out at all (decomposition), or whether the word is stored and recognized as a whole (holistic processing). Some recent studies argue that L2 speakers rely more on whole-word lexical storage than on parsing strategies (Clahsen, Felser, Neubauer, Sato, \& Silva, 2010; Silva \& Clahsen, 2008). However, other studies question this claim (Diependaele, Duñabeitia, Morris, \& Keuleers, 2010; Portin, Lehtonen, \& Laine, 2007). All of these studies are concerned with the processing of derived or inflected words rather than with compounds. Thus, the literature on this point is equivocal and does not directly deal with L2 compound processing. Still, it is possible that the native-nonnative differences observed in some of the studies generalize to compounds. Given that the orthotactic cue effect is conditional upon decomposition, the effect of cue availability should then be smaller for L2 speakers. In our view, though, the opposite is also possible, given the generally low (whole-word) frequency of compounds. L2 speakers might rely more on decomposition because they have not yet established whole-word representations for the compounds.

To summarize, we will test the effect of orthotactic parsing cues in compounds using the lexical decision task in L1 and L2 speakers. These compounds will contain an orthotactic cue ("illegal" bigram) or no cue at the boundary between the compound constituents.

\section{Method}

\section{Participants}

Twenty native speakers of Dutch (three males) and 20 German-Dutch bilinguals (four males), recruited at Radboud University Nijmegen, participated for course credit or money. Participants were, on average, of the ages 24.7 (native speakers) and 24.2 (bilinguals). Bilinguals were German students who had been enrolled in Dutch university programs for at least 2 years. They filled in a language background questionnaire at the end of the experiment (see Table 1).

Furthermore, both groups completed a yes-no vocabulary test for very advanced learners of Dutch, involving 40 lowfrequency Dutch words and 20 nonwords, developed by the first author (see Lemhöfer, Spalek, \& Schriefers, 2008). The mean scores in this test were $91.4 \%$ correct $(S D=3.9)$ for native and $69.8 \%$ correct $(S D=8.3)$ for bilingual speakers.

\section{Materials}

Words We selected 50 pairs of two-constituent noun compounds with identical first constituents, but differing in the legality of the boundary bigram. We will refer to these words as the "cue present" group (e.g., fietsbel; illegal bigram) and "cue absent" group (fietspomp; legal). All illegal bigrams were truly illegal (with a frequency of 0 ) as word/morpheme 
Table 1 Results from the language background questionnaire given to bilingual participants

${ }^{a}$ Self-ratings were given on a scale from 1 (low/rarely) to

7 (high/very often)

\begin{tabular}{lrrr}
\hline & $M$ & $S D$ & Range \\
\hline Age of first contact with Dutch (years) & 21.0 & 2.7 & $16-26$ \\
Years experience with Dutch & 3.2 & 2.8 & $1-14$ \\
Self-ratings $^{\text {a }}$ & & & \\
How often do you read Dutch literature? & 4.8 & 1.5 & $3-7$ \\
How often do you speak Dutch? & 5.0 & 1.5 & $2-7$ \\
How often do you listen to Dutch radio / watch Dutch TV? & 3.1 & 1.9 & $1-7$ \\
Self-rated reading experience in Dutch & 5.0 & 0.9 & $3-6$ \\
Self-rated writing experience in Dutch & 4.8 & 0.9 & $3-7$ \\
Self-rated speaking experience in Dutch & 5.0 & 1.2 & $3-7$ \\
\hline
\end{tabular}

onsets and highly infrequent in any other word position, whereas legal bigrams were frequent on any word position. Bigram frequencies were highly similar across Dutch and German (see Table 2). ${ }^{1}$ None of the words or constituents existed in German in its exact form. None of the compounds contained embedded words across the constituent boundary, or linking elements between the constituents.

Although the first constituents were identical for each word pair, the two stimulus groups were additionally matched for the logarithmic frequency of the second component and of the whole word according to the CELEX database (Baayen, Piepenbrock, \& Gulikers, 1995), number of letters, and (near-) cognate status (both of the second constituent and of the whole word) with respect to German (see Table 2). $t$-tests and Chisquare tests confirmed that there were no significant differences between the two word groups regarding these variables (all $p \mathrm{~s}>0.30$ except for the number of cognates among the second constituent, $p=0.10$ ). A full list of stimuli is provided in the online Supplemental Materials.

Nonwords Fifty pairs of nonwords were constructed in analogy to the compound word sets (e.g., bloefhengel; nonword bloef + "fishing rod," vs. bloefroddel; bloef + "gossip"). Either the first or the second constituent of a nonword (each in 50\% of nonwords) was an existing Dutch word. Nonexisting constituents were pronounceable and orthotactically legal in Dutch. Mean nonword length was 9.7 letters.

\section{Procedure and design}

Participants first carried out the Dutch vocabulary test as an unspeeded lexical decision task that did not contain any compounds except for one word (doornat, "soaked") and one nonword (joutbaag). The "yes" answer was assigned to the participant's dominant hand. In the instruction, speed

\footnotetext{
${ }^{1}$ Three exceptions could not be avoided: "dw" (hoofdwond), "s" (prijslijst), and "sm" (huismerk) are legal bigrams in Dutch, but not in German.
}

was not emphasized, because the test scoring was based on response accuracy only.

For the main experiment, a speed instruction was added (asking participants to react as quickly and as accurately as possible). Otherwise, the instruction for lexical decision remained the same. The first block was a practice block, consisting of a new set of 16 word and 16 nonword compounds. The experiment proper consisted of 200 trials in eight blocks, plus two dummy trials at the beginning of each block.

The order in which the word pairs were presented to the participants was counterbalanced, using four experimental lists of stimuli that were assigned to equal numbers of participants. The two items with the same first constituent always occurred in two different halves of the experiment.

The items were presented in black 28-point Courier letters on white background. Each trial started with the presentation of a fixation point in the middle of the screen for $800 \mathrm{~ms}$. Next, the target appeared and stayed on the screen until the response was given, or until 3,000 ms had passed. The ITI was $700 \mathrm{~ms}$.

After the main experiment, the bilingual participants were given a list of the experimental compounds on paper to indicate which compounds they were and were not familiar with. Furthermore, they filled in the language background questionnaire. The experimental session took about $20 \mathrm{~min}$ for native speakers and $30 \mathrm{~min}$ for bilingual participants.

\section{Results}

Two bilingual participants had to be excluded from the analyses because of high error rates ( $>33 \%)$. Similarly, two word pairs were excluded, because they contained word members that had elicited error rates higher than $60 \%$ even in the native speakers (erfoom and strijkkwintet). ${ }^{2}$ Only the word trials were analyzed.

\footnotetext{
$\overline{2}$ The matching of the stimulus groups was not affected (all $p \mathrm{~s}>0.30$ in $t$ - and chi-square tests).
} 
Table 2 Characteristics of the word stimuli: Means and ranges (between parentheses)

${ }^{a}$ per 1,000 monomorphemic word types

\begin{tabular}{lll}
\hline & $\begin{array}{l}\text { Cue-absent words } \\
\text { (e.g., fietspomp) }\end{array}$ & $\begin{array}{l}\text { Cue-present words } \\
\text { (e.g., fietsbel) }\end{array}$ \\
\hline Total log frequency & $1.28(0.0-3.07)$ & $1.27(0.0-2.50)$ \\
Log frequency of 1st constituent & $3.47(1.90-5.45)$ & $3.47(1.90-5.45)$ \\
Log frequency of 2nd constituent & $3.12(1.72-4.66)$ & $3.13(0.48-4.45)$ \\
Total length in letters & $9.5(6-13)$ & $9.8(6-15)$ \\
Length of 1st constituent & $4.5(3-6)$ & $4.5(3-6)$ \\
Length of 2nd constituent & $4.9(3-9)$ & $5.2(3-11)$ \\
Number of cognates: Whole word & 27 & 28 \\
Number of cognates: 1st constituent & 41 & 41 \\
Number of cognates: 2nd constituent & 38 & 33 \\
Mean Dutch/German bigram frequency of & $10.3 / 9.4$ & $0 / 0$ \\
$\quad$ boundary bigram, onset position & \\
Mean Dutch/German bigram frequency & $19.4 / 19.8$ & $1.7 / 2.0$ \\
$\quad$ of boundary bigram, any position &
\end{tabular}

Table 3 Mean reaction times (RTs, in milliseconds) and error rates (in percentages) for words in the two cue conditions and participant groups, and for nonwords

Standard deviations of means and effects are given between parentheses

\begin{tabular}{|c|c|c|c|c|}
\hline & \multicolumn{2}{|l|}{ Bilinguals } & \multicolumn{2}{|c|}{ Native speakers } \\
\hline & RT & Error rate & RT & Error rate \\
\hline Cue absent (fietspomp) & $952(173)$ & $19.6(11.4)$ & $602(71)$ & $6.3(4.7)$ \\
\hline Cue present (fietsbel) & $913(173)$ & $18.6(9.9)$ & $590(82)$ & $4.7(3.7)$ \\
\hline Effect (cue absent minus cue present) & $39(72)$ & $1.0(8.3)$ & $12(22)$ & $1.6(3.2)$ \\
\hline Nonwords & $1120(215)$ & $13.3(11.6)$ & $703(143)$ & $2.3(1.5)$ \\
\hline
\end{tabular}

Table 4 Word characteristics for the different length groups: Means and ranges (between parentheses)

\begin{tabular}{|c|c|c|c|c|}
\hline & \multicolumn{2}{|l|}{ Short compounds } & \multicolumn{2}{|l|}{ Long compounds } \\
\hline & Cue absent & Cue present & Cue absent & Cue present \\
\hline Total log frequency & $1.40(0.30-3.07)$ & $1.37(0.48-2.50)$ & $1.24(0.00-2.98)$ & $1.29(0.30-2.28)$ \\
\hline Log frequency of 1 st constituent & $3.63(2.37-5.45)$ & $3.63(2.37-5.45)$ & $3.47(2.34-4.71)$ & $3.47(2.34-4.71)$ \\
\hline Log frequency of 2 nd constituent & $3.17(2.34-4.66)$ & $3.21(1.78-4.20)$ & $3.21(2.26-3.93)$ & $3.13(0.48-4.45)$ \\
\hline Total length in letters & $8.29(6-9)$ & $8.29(6-10)$ & $10.81(10-13)$ & $11.14(10-13)$ \\
\hline Length of 1 st constituent & $4.24(3-5)$ & $4.24(3-5)$ & $4.95(4-6)$ & $4.95(4-6)$ \\
\hline Length of 2 nd constituent & $4.05(3-5)$ & $4.05(3-6)$ & $5.86(4-9)$ & $6.19(4-11)$ \\
\hline Number of cognates: Whole word & 8 & 10 & 14 & 15 \\
\hline Number of cognates: 1 st constituent & 15 & 15 & 19 & 19 \\
\hline Number of cognates: 2 nd constituent & 15 & 13 & 17 & 17 \\
\hline
\end{tabular}


Table 5 Mean reaction times (RTs, in milliseconds) and error rates (in percentages) for words split for word length

Standard deviations for means and effects are given between parentheses

\begin{tabular}{|c|c|c|c|c|}
\hline & \multicolumn{2}{|c|}{ Short words } & \multicolumn{2}{|c|}{ Long words } \\
\hline & RT & Error rate & $\mathrm{RT}$ & Error rate \\
\hline \multicolumn{5}{|l|}{ Bilinguals } \\
\hline Cue absent (roomijs) & $912(202)$ & $22.0(15.2)$ & $974(159)$ & $16.9(9.4)$ \\
\hline Cue present (roomkaas) & $878(155)$ & $20.1(12.2)$ & $939(196)$ & $17.5(10.6)$ \\
\hline Effect (cue absent minus cue present) & $34(78)$ & $1.9(12.8)$ & $35(106)$ & $-0.6(9.6)$ \\
\hline \multicolumn{5}{|l|}{ Native speakers } \\
\hline Cue absent (vrachtrijder) & $568(71)$ & $2.9(3.6)$ & $631(77)$ & $9.5(8.2)$ \\
\hline Cue present (vrachtverkeer) & $576(84)$ & $6.7(6.4)$ & $599(86)$ & $2.9(3.2)$ \\
\hline Effect (cue absent minus cue present) & $-8(32)$ & $-3.8(5.5)$ & $32(35)$ & $6.6(7.9)$ \\
\hline
\end{tabular}

The mean error rate for words was $9.7 \%$. For the analysis of reaction times (RTs), erroneous responses were excluded pairwise (i.e., together with their matched item) for each participant. Outliers that lay more than two standard deviations away from the item and participant mean were excluded in the same manner. This way, a total of $81.0 \%$ of the original data were used in the RT analyses (native speakers, 90.3\%; bilinguals, $70.8 \%$ ). The mean RTs and error rates are given in Table 3 .

\section{Reaction times}

Because of the extreme differences in RTs between the two participant groups (more than $300 \mathrm{~ms}$ on average), we $z$-transformed the RTs separately for each group to make them more comparable to each other. ${ }^{3}$ Repeated measures ANOVAs across participant and item means were carried out on $z$-transformed RTs with cue presence as a within-participants and within-items pairs factor, and participant group as a between-participants, within-items factor. There was a main effect of cue presence, $F_{1}(1,36)=$ 9.87, $p<0.01 ; F_{2}(1,47)=4.07, p<0.05$. Words without cues were recognized more slowly (untransformed mean $\mathrm{RT}=777 \mathrm{~ms})$ than those with cues $(751 \mathrm{~ms})$. Due to the standardization by $z$-transformation, there was no effect of participant group (both $F_{\mathrm{S}}<1$ ). Crucially, cue presence and participant group did not interact (both $F_{\mathrm{S}}<1$ ). ${ }^{4}$ When adding experimental half as a factor to investigate the effect of first constituent repetition, it did not interact with any other factor (all $p$ s $>0.35$ ).

\footnotetext{
${ }^{3}$ The effect of participant group was highly significant when analyzing untransformed RTs, $F_{1}(1,36)=64,80, p<0.001 ; \mathrm{F}_{2}(1$, 47) $=589.84, p<0.001$

${ }^{4}$ The effect for native speakers was significant (marginally across items) when analyzed separately for this group, $t_{1}(19)=2.33, p<$ $0.05 ; t_{2}(47)=1.30, p=0.095$.
}

\section{Error rates}

Error rates were arcsine transformed to correct for nonnormality in their distributions and were subjected to ANOVAs that were parallel to those carried out on RTs. There was no effect of cue presence, $F_{1}(1,36)=$ $1.77, p=0.19 ; F_{2}<1$. Not surprisingly, bilinguals had higher error rates $(19.1 \%)$ than did native speakers $(5.5 \%)$, $F_{1}(1,36)=37.42, p<0.001 ; F_{2}(1,47)=56.25, p<$ 0.001. Neither the interaction of the two factors, nor interactive effects involving experimental half, were significant (all $F \mathrm{~s}<1)$.

\section{Unfamiliar words}

Excluding words participant-wise that had been marked as unfamiliar $(10.3 \%)$ together with their pair partners (together, 17.8\%) did not change the RT results for the bilinguals: There was a significant $37-\mathrm{ms}$ cue-presence effect in the RTs, $t(17)=2.42, p<0.05$, and an insignificant $2.3 \%$ effect in the error rates, $t(17)=1.12$, $p=0.14$.

Long versus short compounds

After having confirmed an orthotactic effect, we investigated in a post hoc analysis whether the cue effect was modulated by the length of the compounds, as was suggested by Bertram et al. (2004). Possibly, speakers decompose only long compounds (longer than approximately nine letters), whereas they process short ones holistically. If so, the cue effect should arise for long words only. Therefore, we divided the word pairs into those with long and short words (longer or shorter than 10 letters, which was the median length of our compounds). ${ }^{5}$ Six word pairs had to be excluded from this analysis, because their two members could not be assigned to the same length

\footnotetext{
$\overline{{ }^{5} \text { An exception }}$ was one word pair with nine and 10 letters, which was assigned to the shorter group for the sake of equal group sizes.
} 
group. The 42 remaining pairs were split into two groups of 21 pairs each. ${ }^{6}$ Table 4 shows the word characteristics for the two length groups. The mean RTs and error rates for the conditions, split for word length, are reported in Table 5.

A repeated measures ANOVA with word length (short vs. long) as an additional factor was carried out on the $z$ transformed RTs and on arcsine-transformed error rates. We report only the relevant interactions involving word length and cue presence. For RTs, the interaction of cue presence and word length was significant across participants, but not across items, $F_{1}(1,36)=5.43, p<0.05 ; F_{2}(1,40)=1.26, p=0.27$. However, there was a significant three-way interaction of cue presence, word length, and participant group, $F_{1}(1,36)$ $=4.75, p<0.05 ; F_{2}(1,40)=4.21, p<0.05$. Similarly, for error rates, the three factors interacted significantly, $F_{1}(1,36)$ $=10.15, p<0.01 ; F_{2}(1,40)=3.99, p=0.05$.

Separate analyses for bilingual and native speakers showed that word length did not interact with the cue effect for bilinguals (all $F_{\mathbf{S}}<1$ ), whereas this interaction was significant for native speakers: RTs, $F_{1}(1,19)=12.9, p<0.01 ; F_{2}(1$, $40)=4.21, p<0.05$; error rates, $F_{1}(1,19)=16.56, p<0.001$; $F_{2}(1,40)=7.64, p<0.01$. Pairwise $t$-tests showed that the cue effect for native speakers' RTs was not reliable for short words, $t_{1}(19)=-1.16, p=0.26 ; t_{2}(20)=-0.98, p=0.34$, but was significant for long ones marginally across items: $t_{1}(19)$ $=4.16, p<0.001 ; t_{2}(20)=1.87, p=0.08$. In the native speakers' error rates, there was a cue effect in the predicted direction for long words that was marginally significant in the item analysis, $t_{1}(19)=3.34, p<0.01 ; t_{2}(20)=1.73, p=$ 0.09 , whereas it went into the opposite direction for short words, $t_{1}(19)=-3.21, p<0.01 ; t_{2}(20)=-2.51, p<0.05$.

\section{Discussion}

Our main result, shorter recognition latencies for compounds containing an orthotactic parsing cue (i.e., a bigram at the constituent boundary that would be illegal within a morpheme), shows that both bilinguals and native speakers of Dutch benefit from the presence of such a cue during compound recognition. This finding suggests that sublexical information is used during compound parsing and aids the identification of the constituents. The parsing cue effect is at odds with classical left-to-right parsing accounts, which entail a parsing mechanism that is independent of the salience of the constituent boundary (see, e.g., Libben, 1994; Taft \& Forster, 1976). Our results are in line with eye-movement data on sentence reading from Finnish, which, however, belongs to a different language family (Bertram et al., 2004). Furthermore, the faster lexical

\footnotetext{
${ }^{6}$ Within the length groups, variables remained matched across the cue absent/present sets (all $p \mathrm{~s}>0.24$ in $t$-and chi-square tests).
}

decision responses in the presence of a parsing cue are in accordance with accounts of morphological parsing that incorporate a decomposition route (Duñabeitia et al., 2009; Koester et al., 2007; Kuperman et al., 2009).

On first sight, the nondifferent size of the cue effect for bilinguals and native speakers seems inconsistent with our initial supposition of possible differences in the size of the cue effect between these two groups. Due to slower access to a compounds' constituents, we had hypothesized that L2 speakers might rely more on orthotactic parsing cues because of their greater availability, especially when they overlap between L1 and L2, as in the present case. In that case, there should have been an overall larger effect of cue presence for nonnative speakers, which was not what we observed.

However, our additional analyses on the modulating role of word length suggest that rather than the simple quantitative difference we had initially expected, there are qualitative differences between native and nonnative speakers with respect to the cue effect. Native speakers showed the cue effect for long, but not for short compounds. Together with previous evidence (Bertram \& Hyönä, 2003; Bertram et al., 2004), this data pattern suggests that short compounds are accessed primarily via the whole-word route, whereas long compounds are decomposed (using, possibly among others, orthotactic cues). In contrast, this interaction of compound length and cue effect was absent for bilingual speakers. This indicates that bilinguals decompose all compounds irrespective of length, and that they use orthotactic cues for this decomposition.

Thus, as compared with the native speakers, bilinguals showed broader evidence of decomposition, not with respect to effect size, but with respect to the generality of the effect across word length. This is contradictory to the hypothesis that L2 speakers rely more on whole-word lexical storage and less on decomposition than native speakers, a claim made in some studies on inflected word forms (e.g., Clahsen et al., 2010). However, given the fundamental differences between compounds and inflections, our results do not speak to the debate on the processing of inflections by L2 speakers. Our data pattern fits more with the notion that L2 speakers might not (yet) have established whole-word representations for those compounds for which native speakers have done so (i.e., short compounds). This is likely to be a consequence of lower subjective frequencies for L2 compounds, given that wholeword representations may be restricted to words above a certain frequency limit (Alegre \& Gordon, 1999; Lehtonen \& Laine, 2003; but see McCormick, Brysbaert, \& Rastle, 2009).

In summary, the present study adds to the sparse and mixed literature by providing evidence for an important role of orthotactic information in decomposing compounds. It has to be noted, though, that given the overlap of Dutch and German bigram characteristics in our stimuli, our data do not speak to the question of whether it was German (L1) 
or Dutch (L2) orthotactics that had an effect on the bilingual speakers. The present study was not designed to disentangle the differential role of L1 versus L2 orthotactic cues in compound parsing, nor would it be straightforward to do so in highly related languages such as Dutch and German. Our study shows that orthotactic cues that are highly familiar to the participants are used in compound processing. Further research should address whether L2 cues that differ from those in L1 are available to L2 speakers, as has been shown in the auditory domain (Weber \& Cutler, 2006).

Finally, in methodological terms, our results show that the parsing cue effect can serve as an indicator of decompositional processes in compound reading. This represents an alternative to the two predominant paradigms in (single-word) compound recognition researchnamely, constituent priming (e.g., Duñabeitia et al., 2009; Zwitserlood, 1994) and the orthogonal manipulation of constituent versus compound frequencies (e.g., Bertram \& Hyönä, 2003; Kuperman et al., 2009).

Author Note We thank Julia Lennertz for running the experiment, and Jon Andoni Duñabeitia for his helpful comments on earlier versions of the manuscript. This research was supported by a "veni" grant from the Netherlands Organization for Scientific Research (NWO) to K. L.

Open Access This article is distributed under the terms of the Creative Commons Attribution Noncommercial License which permits any noncommercial use, distribution, and reproduction in any medium, provided the original author(s) and source are credited.

\section{References}

Alegre, M., \& Gordon, P. (1999). Frequency effects and the representational status of regular inflections. Journal of Memory and Language, 40, 41-61. doi:10.1006/jmla.1998.2607

Bayen, R. H., Piepenbrock, R., \& Gulikers, L. (1995). The CELEX lexical database (Release 2) [CD ROM]. Philadelphia: Linguistic Data Consortium, University of Pennsylvania.

Bertram, R., \& Hyönä, J. (2003). The length of a complex word modifies the role of morphological structure: Evidence from eye movements when reading short and long Finnish compounds. Journal of Memory and Language, 48, 615-634. doi:10.1016/ S0749-596X(02)00539-9

Bertram, R., Pollatsek, A., \& Hyönä, J. (2004). Morphological parsing and the use of segmentation cues in reading Finnish compounds. Journal of Memory and Language, 51, 325-345. doi:10.1016/j. jm1.2004.06.005

Clahsen, H., Felser, C., Neubauer, K., Sato, M., \& Silva, R. (2010). Morphological structure in native and nonnative language processing. Language Learning, 60, 21-43. doi:10.1111/j.14679922.2009.00550.x

Diependaele K, Duñabeitia JA, Morris J, \& Keuleers E (2010). Fast morphological effects in first and second language word recognition. Manuscript submitted for publication.
Dijkstra, T., \& van Heuven, W. J. B. (2002). The architecture of the bilingual word recognition system: From identification to decision. Bilingualism: Language and Cognition, 5, 175-197. doi:10.1017/S1366728902003012

Duñabeitia, J. A., Laka, I., Perea, M., \& Carreiras, M. (2009). Is Milkman a superhero like Batman? Constituent morphological priming in compound words. European Journal of Cognitive Psychology, 21, 615-640. doi:10.1080/09541440802079835

Inhoff, A. W., Radach, R., \& Heller, D. (2000). Complex compounds in German: Interword spaces facilitate segmentation but hinder assignment of meaning. Journal of Memory and Language, 42, 23-50. doi:10.1006/jmla.1999.2666

Koester, D., Gunter, T. C., \& Wagner, S. (2007). The morphosyntactic decomposition and semantic composition of German compound words investigated by ERPs. Brain and Language, 102, 64-79. doi:10.1016/j.bandl.2006.09.003

Kuperman, V., Schreuder, R., Bertram, R., \& Baayen, R. H. (2009). Reading polymorphemic Dutch compounds: Toward a multiple route model of lexical processing. Journal of Experimental Psychology: Human Perception and Performance, 35, 876-895. doi:10.1037/a0013484

Lehtonen, M., \& Laine, M. (2003). How word frequency affects morphological processing in monolinguals and bilinguals. Bilingualism: Language and Cognition, 6, 213-225. doi:10.1017/ S1366728903001147

Lemhöfer, K., Spalek, K., \& Schriefers, H. (2008). Cross-language effects of grammatical gender in bilingual word recognition and production. Journal of Memory and Language, 59, 312-330. doi:10.1016/j.jml.2008.06.005

Libben, G. (1994). How is morphological decomposition achieved? Language and Cognitive Processes, 9, 369-391. doi:10.1080/ 01690969408402124

McCormick, S. F., Brysbaert, M., \& Rastle, K. (2009). Is morphological decomposition limited to low-frequency words? Quarterly Journal of Experimental Psychology, 62, 1706-1715. doi:10.1080/17470210902849991

Pollatsek, A., Hyönä, J., \& Bertram, R. (2000). The role of morphological constituents in reading Finnish compound words. Journal of Experimental Psychology: Human Perception and Performance, 26, 820-833.

Portin, M., Lehtonen, M., \& Laine, M. (2007). Processing of inflected nouns in late bilinguals. Applied Psycholinguistics, 28, 135-156.

Rapp, B. C. (1992). The nature of sublexical orthographic organization: The bigram trough hypothesis examined. Journal of Memory and Language, 31, 33-53. doi:10.1016/0749-596X(92) 90004-H

Rastle, K., Davis, M. H., \& New, B. (2004). The broth in my brother's brothel: Morpho-orthographic segmentation in visual word recognition. Psychonomic Bulletin and Review, 11, 1090-1098.

Seidenberg, M. S. (1987). Sublexical structures in visual word recognition: Access units or orthographic redundancy? In M. Coltheart (Ed.), Attention and performance XII: The psychology of reading (pp. 245-263). Hove: Erlbaum.

Silva, R., \& Clahsen, H. (2008). Morphologically complex words in L1 and L2 processing: Evidence from masked priming experiments in English. Bilingualism: Language and cognition, 11, 245-260. doi:10.1017/S1366728908003404

Taft, M., \& Forster, K. I. (1976). Lexical storage and retrieval of polymorphemic and polysyllabic words. Journal of Verbal Learning and Verbal Behavior, 15, 607-620.

Weber, A., \& Cutler, A. (2006). First-language phonotactics in second-language listening. Journal of the Acoustical Society of America, 119, 597-607. doi:10.1121/1.2141003

Zwitserlood, P. (1994). The role of semantic transparency in the processing and representation of Dutch compounds. Language and Cognitive Processes, 9, 341-368. doi:10.1080/01690969408402123 